\title{
Development of a System to Support Surgical Safety-I and Safety-II. Implementation of Resilient Surgical Healthcare for Bleeding Incidents in Thoracic Surgery
}

\author{
Takanori Ayabe ${ }^{1,2^{*}}$, Masaki Tomita1, Ryo Maeda1, Manabu Okumura², Kunihide Nakamura3 \\ ${ }^{1}$ Division of Thoracic and Breast Surgery, Department of Surgery, Faculty of Medicine, University of Miyazaki, Miyazaki, Japan \\ ${ }^{2}$ Department of Patient Safety Management, University of Miyazaki Hospital, Miyazaki, Japan \\ ${ }^{3}$ Division of Cardiovascular Surgery, Department of Surgery, University of Miyazaki Hospital, Miyazaki, Japan \\ Email: tayabe@med.miyazaki-u.ac.jp
}

How to cite this paper: Ayabe, T., Tomita, M., Maeda, R., Okumura, M. and Nakamura, K. (2020) Development of a System to Support Surgical Safety-I and Safety-II. Implementation of Resilient Surgical Healthcare for Bleeding Incidents in Thoracic Surgery. Surgical Science, 11, 405-427. https://doi.org/10.4236/ss.2020.1112043

Received: November 17, 2020

Accepted: December 15, 2020

Published: December 18, 2020

Copyright $\odot 2020$ by author(s) and Scientific Research Publishing Inc. This work is licensed under the Creative Commons Attribution International License (CC BY 4.0).

http://creativecommons.org/licenses/by/4.0/

(c) (i) Open Access

\begin{abstract}
Background: Since bleedings in surgery are infrequent and inexperienced, we always try to proceed with surgery assuming a crisis situation, adhere to routine procedures and its standardization. We focus on the bleeding accidents and reveal how to implement a resilient healthcare theory. By clarifying the Safety-I and Safety-II, we developed a system to support surgical safety based on the surgeon's individual, team, and organization. Material and Methods: We searched 25 cases of bleeding incidents in thoracic surgery, which were obtained from the database of the Project to Collect Medical Near-Miss/Adverse Event Information of the Japan Council of Quality Health Care in April 2018. Retrospectively, we analyzed 13 hemorrhage cases in our department between July 2002 and March 2020. We studied their surgical factors such as procedures, sites and causes of bleeding, response, treatment, and outcomes. Results: The causes of bleeding included damage of the adhesion detachment, insertions of automatic sutures and forceps, detachment of ultrasonic scalpel, vascular taping, removal of resected lung, lymph node dissection, exfoliation of the infiltrated adventitia of vessels, pull-out of vessel, gauze attachment with staple cut-line of vessel, thoracoscopic collision, infectious vascular rupture, detachment of vascular ligature, and suction tube hit. We summarized the variation in the usual controllable and unexpected uncontrollable bleeding and learned how to respond and treat them. We built up the balanced combination of Safety-I and Safety-II in the daily routine work in normal surgery, the patient's individual factors, the massive bleeding, and its life-threatening crisis. Conclusions: We can learn how to prevent and respond to bleeding acci-
\end{abstract}


dents by developing a system to support surgical safety (Safety-I and Safety-II). We can flexibly respond to unexpected bleeding disturbances under constraints by adjusting the surgeon's individuals, team, and organization.

\section{Keywords}

Incident, Safety-I, Safety-II, Resilient Healthcare, Surgical Safety

\section{Introduction}

Until now, the basics of industrial safety have been "safety means that there are no accidents" and "learning from failures". To this end, incident cases have been collected, the root causes have been analyzed, recurrence prevention measures have been taken, and these have been introduced into the field, that is called "Safety-I".

In Japan, similar efforts in medical care began in 1999, and today, various patient safety measures are being implemented at medical institutions in Japan and overseas, but they face common challenges.

This includes the following 1), 2), and 3).

1) There are many incidents due to non-compliance with safety procedures.

2) Reliance on standard safety procedures reduces the flexibility of the healthcare professionals.

3) There is no appropriate index to measure the improvement of safety, and the effect of measures cannot be evaluated.

These problems are experienced not only in healthcare but also in other industries.

Dr. Erik Hollnagel [1]-[8], who recently advocated resilience engineering theory, calls traditional safety management aimed at eliminating failures Safety-I. This alone is the limit, and the approach aimed at doing things well in the face of disturbances and constraints is called Safety-II.

Figure 1 shows the relationship between Safety-I and Safety-II in Resilience Surgical Healthcare. From the latest patient safety perspective, it is important to learn from successful cases of surgery, not to mention learning from surgery failures. Safety-I is to reduce surgical failure. Surgical procedure and standardization are the first. It is desired that "Make a mold and protect the mold". This is the so-called "traditional patient safety". In contrast, Safety-II is to increase surgical success. It is centered on learning from what's going on and improving the resilience ability. This is "future patient safety". Both the concepts of Safety-I and Safety-II are important for surgical safety and should be balanced in the combination of Safety-I + Safety-II.

Professor Kazue Nakajima [9], a world authority on resilient healthcare theory in Japan, states that the following three perspectives are important. In order to practice Safety-II, 1) target daily work, 2) broadly view the system, and 3) focus 


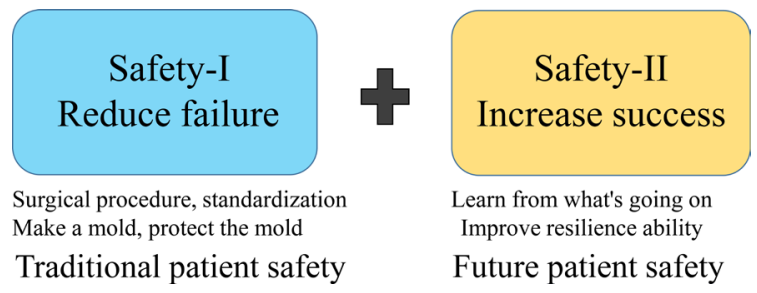

Figure 1. Relationship between Safety-I and Safety-II in Resilient Surgical Healthcare. The latest patient safety perspective (learned from successful cases of surgery, not from the failure of surgery). Safety-I is to reduce failure. Surgical procedure and standardization. Make a mold and protect the mold. This is traditional patient safety. In contrast, Safety-II is to increase success. Learn from what's going on. Improve resilience ability. This is future patient safety. Both Safety-I and Safety-II are important for the implementation of surgical safety.

on interaction. Resilience means the ability of individuals, teams, and organizations to make various adjustments (adjustments and ingenuity) according to the situation and flexibly respond. In this new approach to safety (Safety-II), "safety is defined as the ability to perform the required tasks and functions even in unexpected situations." Focusing on "successful things" on the premise that "even if you do the same thing, you may succeed or fail. Therefore, the basis of failure and success is the same."

Medical care in university hospitals is a huge and complex system, and is characterized by uncertainty. We evaluated the outcomes of multidisciplinary-reported incidents regarding patient safety management at the Special Functioning Hospital [10]. We have introduced the WHO Surgical Safety Checklist to a multidisciplinary team at a university hospital and reported on the changes in safety attitudes [11]. We have also analyzed and studied incidents reported by surgeons in "surgical patient safety" [12]. In the study of the resilience engineering field, we implemented resilience healthcare theory in thoracic surgery and clarified how to bring Work-As-Imagined and Work-As-Done closer to each other in the surgical team [13]. We have also summarized the hidden interactions between members of the surgical team as an extension of resilience engineering to surgery [14].

In respiratory surgery-related operations, such as lung cancer surgery, no one wants to encounter potentially fatal intraoperative and postoperative bleeding and reopening cases. As the number of lobectomy experiences increases, bleeding events must be encountered at a certain frequency and the response to bleeding must be assumed. According to the annual report of the Japanese Association for Thoracic Surgery [15], 23,411 of 35,667 patients with lung cancer underwent video-assisted thoracic surgery (VATS) in 2012, and the number of VATS surgery for non-small cell lung cancer began to increase. The incidents and accidents have been raised about the safety of thoracic surgery, with reports of catastrophic intraoperative complications [16]-[23] including bleeding, transection of an entire artery, vein, or bronchus, contralateral nerve palsy and bronchial injury. 
We investigated the respiratory surgery-related bleeding cases reported to the Project to Collect Medical Near-Miss/Adverse Event Information of the Japan Council of Quality Health Care [24]. We collected the incident case reports (mainly bleeding cases) related to chest surgery, and based on the resilient engineering theory and the patient safety perspectives, this study was designed for a detailed consideration.

We reviewed our cases regarding the intraoperative pulmonary artery injury and bleeding incidents that we experienced, and also examined and considered them with the cases of thoracic surgery bleeding reported by the Medical Accident Investigation Program of the Japan Agency for Medical Evaluation [24].

In this study, we analyzed bleeding incident cases, consider the results obtained in Safety-I and Safety-II in resilience engineering, and the report of how to develop and implement a system to support surgical safety.

\section{Materials and Methods}

\subsection{Study Design}

We used the database from the Project to Collect Medical Near-Miss/Adverse Event Information of the Japan Council of Quality Health Care [24]. Figure 2 is a flow diagram of the searched results using this database. In April, 2018, the keyword of "thoracic surgery" was used, and 211 cases were searched from the database. Eighty-six cases were hit by searching the word of "hemorrhage" or

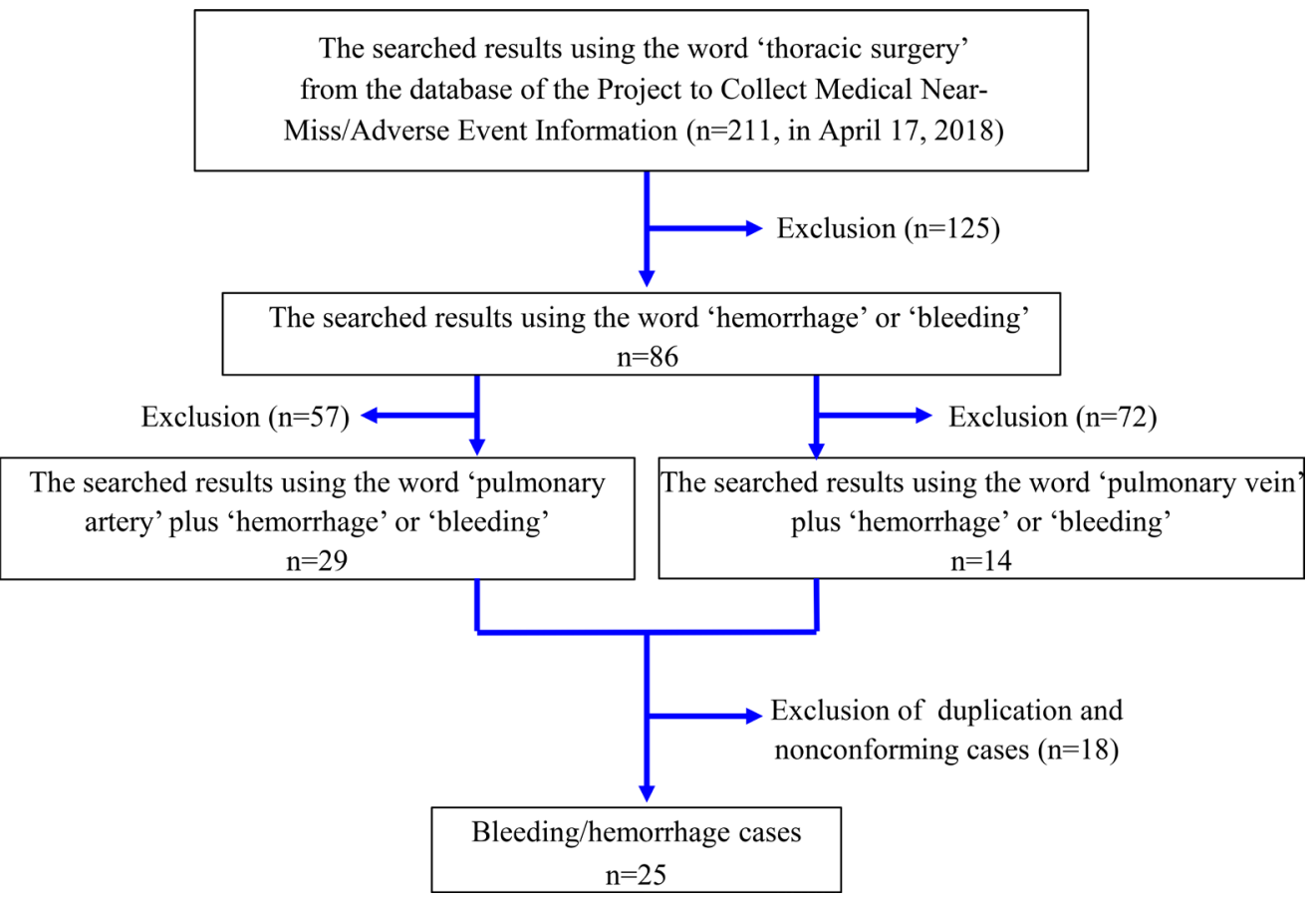

Figure 2. The database of the Project to Collect Medical Near-Miss/Adverse Event Information (in April 17, 2018). Flow of the search by use of the word of "thoracic surgery" ( $n=211)$, "hemorrhage" or "bleeding" ( $n=86)$, pulmonary artery' $(n=29)$ and "pulmonary vein" $(n=14)$. After exclusion of duplication and nonconformance cases, as a bleeding and hemorrhage case, 25 cases were used in this study. 
"bleeding" in 211 cases and the remaining 125 cases were excluded. The searching word of "pulmonary artery" hit 29 cases and another searching word of "pulmonary vein" hit 14 cases. After the exclusion due to the duplicated cases and the nonconformance reports, 25 cases were finally selected as the "bleeding/hemorrhage cases in thoracic surgery".

Between July 2002 and March 2020, we retrospectively selected 13 experienced cases of intraoperative and postoperative hemorrhagic incidents in our department of thoracic surgery. This study was approved by the University of Miyazaki Hospital Clinical Research Ethics Board (No. O-0736 and No. O-0737) in July 2020 .

\subsection{Analysis Items}

We analyzed the searched cases $(n=25)$ and the experienced cases $(n=13)$ based on the items of surgical sites, procedures, site of bleeding, perioperative period, causes of bleeding, response and treatment, support by cardiovascular surgeon, circulation auxiliary equipment, and prognosis. Table 1 shows the case details of the bleeding accidents $(n=25)$ from the database of the Project to Collect Medical Near-Miss/Adverse Event Information and Table 2 shows our experienced cases $(n=13)$ of bleeding accidents in our department.

\subsection{Analysis of Safety-I and Safety-II Based on Resilience Healthcare Theory}

Dr. Erik Hollnagel provided a deep insight into the ideal way of safety management in social technology systems, focused on "failure", and called safety management aimed at "eliminating failure" as "Safety-I". Focusing on "how daily work is done under disturbance and constraints", "making things go well", it is called "Safety-II", and the difference in approach is clearly shown [1].

Table 3 displays the features and differences of Safety-I and Safety-II [9]. Safety-I recognizes the limitations of Safety-II and has evolved from a critical standpoint. However, Safety-I and Safety-II are complementary to each other, and safety management of social technology systems also requires therapy, and Safety-II is not a substitute for Safety-I [9].

In order to develop resilience engineering theory into surgical safety, it is necessary to clarify the specific methods for the following four items.

1) Observe the daily work performed at the surgical site,

2) Understand various "adjustments" performed by the surgeon according to the surgical situation,

3) Predict "functional resonance" that causes unexpected situations,

4) Take preventive measures.

In this study, we observed the surgical work during thoracic surgery from the viewpoint of surgical safety, collected adjustment cases especially for bleeding cases, and analyzed the background factors.

Surgical care is a complex system and is characterized by uncertainty. The 
Table 1. The case details of the bleeding accidents $(n=25)$ from the database of the Project to Collect Medical Near-Miss/Adverse Event Information.

\begin{tabular}{|c|c|c|c|c|c|c|c|c|c|}
\hline 造 & 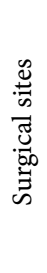 & 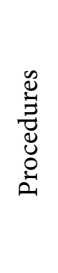 & 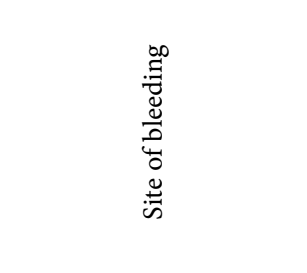 & 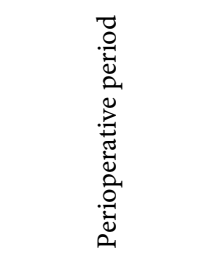 & 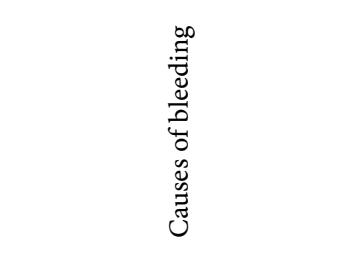 & 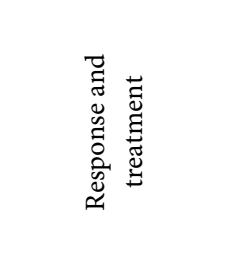 & 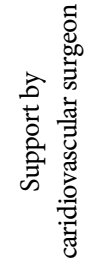 & 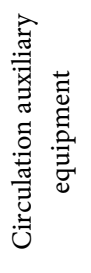 & 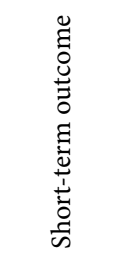 \\
\hline 1 & $\mathrm{~L}$ & UL & PA in upper lobe & Postoperative & $\begin{array}{l}\text { Adhesion peeling with } \\
\text { ultrasonic scalpel injury }\end{array}$ & Suture hemostasis & & & Survival \\
\hline 2 & $\mathrm{~L}$ & UL & $\begin{array}{l}\text { PA 1st brnch in upper } \\
\text { lobe }\end{array}$ & Intraoperative & $\begin{array}{l}\text { When one lung ventilation is } \\
\text { released }\end{array}$ & Suture repair & $\mathrm{O}$ & PCPS & Survival \\
\hline 3 & $\mathrm{~L}$ & UL & Proximal site of PA & Intraoperative & $\begin{array}{l}\text { At the time of vascular } \\
\text { forceps insetion }\end{array}$ & Hemostasis & & & Survival \\
\hline 4 & $\mathrm{~L}$ & $\mathrm{UL}$ & PA branch in upper lobe & Intraoperative & Forceps insertion injury & Hemostasis & & & Survival \\
\hline 5 & $\mathrm{~L}$ & UL & $\begin{array}{l}\text { PA 1st branch in upper } \\
\text { lobe }\end{array}$ & Intraoperative & Injury with suture needles & Suture hemostasis & $\mathrm{O}$ & $\mathrm{CPB}$ & Survival \\
\hline 6 & $\mathrm{~L}$ & UL & $\mathrm{A}^{3}$ branch & Intraoperative & Adhesion & Pn & O & & Survival \\
\hline 7 & $\mathrm{~L}$ & UL & $\mathrm{A}^{1+2 \mathrm{a}}$ branch & Intraoperative & Vessel Sealing & Pn & & & Death \\
\hline 8 & $\mathrm{~L}$ & $\mathrm{UL}$ & Right atrial cleavage & Intraoperative & - & Suture closure & $\mathrm{O}$ & $\mathrm{CPB}$ & Unknown \\
\hline 9 & $\mathrm{~L}$ & - & $\mathrm{PA}$ & - & - & Repair & $\mathrm{O}$ & & Unknown \\
\hline 10 & $\mathrm{R}$ & LL & $\begin{array}{l}\text { Intermediate PA trunk } \\
\text { rear surface }\end{array}$ & Intraoperative & Insertion of automatic suture & $\begin{array}{l}\text { Life-saving } \\
\text { treatment for } \\
\text { cardiac arrest }\end{array}$ & & & Death \\
\hline 11 & $\mathrm{R}$ & UL & $\mathrm{A}^{3}$ branch & Intraoperative & Adhesion & $\begin{array}{l}\text { Suture closure of } \\
\text { main PA in } \\
\text { cardiac sac }\end{array}$ & & & Death \\
\hline 12 & $\mathrm{R}$ & UL & $\mathrm{A}^{2}$ branch root & Intraoperative & $\begin{array}{l}\text { During taping of the main PA } \\
\text { trunk }\end{array}$ & $\begin{array}{l}\text { Hemostasis of the } \\
\text { damaged site }\end{array}$ & & & Death \\
\hline 13 & $\mathrm{R}$ & UL & PA & Intraoperative & - & $\begin{array}{l}\text { Hemostasis, } \\
\text { partial resection of } \\
\text { the lung }\end{array}$ & & & Survival \\
\hline 14 & $\mathrm{R}$ & UL & $\mathrm{A}^{2}$ branch root & $\begin{array}{l}\text { Intraoperative/p } \\
\text { ostoperative }\end{array}$ & $\begin{array}{l}\text { Postoperative bleeding at the } \\
\text { same site of hemostasis due to } \\
\text { the forceps insertion injury }\end{array}$ & Completion Pn & & PCPS & Survival \\
\hline 15 & $\mathrm{R}$ & LL & - & Intraoperative & Vascular anastomosis & Suture closure & & PCPS & Survival \\
\hline 16 & $\mathrm{R}$ & UL & $\begin{array}{l}\text { PA damage when the } \\
\text { excision of resected lung }\end{array}$ & Intraoperative & Massive bleeding & $\begin{array}{l}\text { Thoracotomy, } \\
\text { hemostasis }\end{array}$ & & & Survival \\
\hline 17 & $\mathrm{R}$ & UL & - & Postoperative & Postoperative hemorrhage & $\begin{array}{c}\text { Sudden vital } \\
\text { change just before } \\
\text { hemostasis }\end{array}$ & & & Death \\
\hline 18 & $\mathrm{R}$ & LL & - & Postoperative & Mass hemorrhage & $\begin{array}{l}\text { Life-saving } \\
\text { treatment for } \\
\text { cardiac arrest }\end{array}$ & & & Death \\
\hline 19 & $\mathrm{~L}$ & LL & Cut-end of lower PV & $\begin{array}{l}\text { Postoperative, } \\
\text { extubation }\end{array}$ & $\begin{array}{l}\text { Hemodynamic changes due } \\
\text { to backing during extubation }\end{array}$ & $\begin{array}{l}\text { Suture hemostasis } \\
\text { in cardiac sac }\end{array}$ & & & Unknown \\
\hline
\end{tabular}




\section{Continued}

\begin{tabular}{|c|c|c|c|c|c|c|c|c|c|}
\hline 20 & $\mathrm{~L}$ & $\mathrm{LL}$ & Upper PV damage & Intraoperative & Injury & PCPS & $\mathrm{O}$ & $\mathrm{CPB}$ & Death \\
\hline 21 & $\mathrm{~L}$ & Pn & $\begin{array}{c}\text { Near the confluence of } \\
\text { Superior vena cava and } \\
\text { azygous vein }\end{array}$ & Intraoperative & Lymph node (\#4L) dissection & $\begin{array}{l}\text { Suture closure of } \\
\text { the bleeding part }\end{array}$ & & & Death \\
\hline 22 & $\mathrm{~L}$ & Pn & $\mathrm{PV}$ in caridiosac & Intraoperative & $\begin{array}{l}\text { Automatic suture injury due } \\
\text { to the manupulation in } \\
\text { cardiac sac }\end{array}$ & $\begin{array}{l}\text { Uncontrollable } \\
\text { bleeding sites }\end{array}$ & & & Death \\
\hline 23 & $\mathrm{~L}$ & S3-Seg & Aortic arch & Intraoperative & $\begin{array}{l}\text { Peeling of the Infiltrated } \\
\text { outer membrane of PA }\end{array}$ & $\begin{array}{l}\text { Repair of aortic } \\
\text { arch }\end{array}$ & $\mathrm{O}$ & $\mathrm{CPB}$ & Survival \\
\hline 24 & $\mathrm{~L}$ & S3-Seg & Aortic arch & Intraoperative & $\begin{array}{l}\text { Peeling of the infiltrated outer } \\
\text { membrane of PA and } \\
\text { manupilation of the } \\
\text { automatic suture }\end{array}$ & $\begin{array}{c}\text { Repair of aortic } \\
\text { arch }\end{array}$ & $\mathrm{O}$ & $\mathrm{CPB}$ & Survival \\
\hline 25 & $\mathrm{~L}$ & LL & $\begin{array}{l}\text { Descending thoracic } \\
\text { aorta }\end{array}$ & Intraoperative & Automatic suture injury & $\begin{array}{c}\text { Repair of } \\
\text { descending } \\
\text { thoracic aorta }\end{array}$ & $\mathrm{O}$ & & Survival \\
\hline
\end{tabular}

Bleeding cases were accidental and should be handled with care. Patient age, gender, and clinical background were anonymized and only short-term outcomes were described upon survival and death. L: Left, R: Right, Pn: Pneumonectomy, Seg: Segmentectomy PA: Pulmonary artery, PV: Pulmonary vein, UL: Upper lobectomy, LL: Lower lobectomy, CPB: Cardiopulmonary bypass, PCPS: Percutaneous cardiopulmonary support

Table 2. The case details of the bleeding accidents $(n=13)$ in our department.

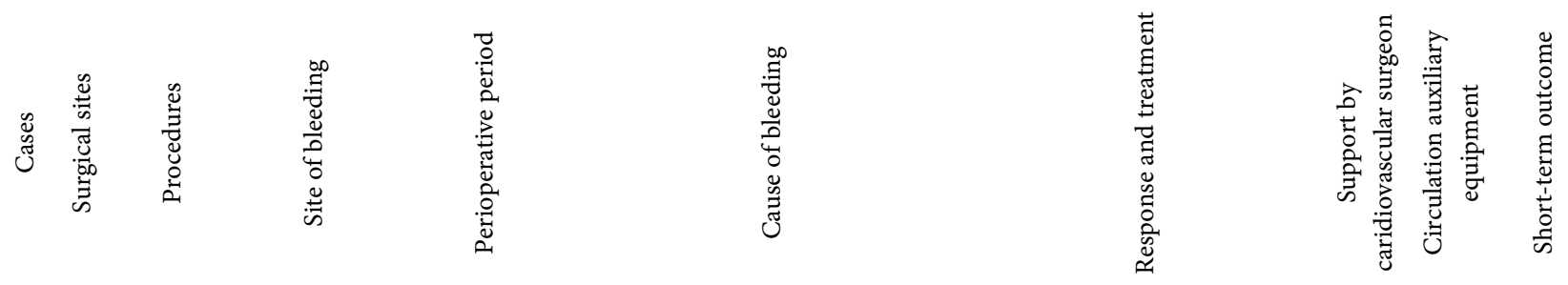

$1 \quad \mathrm{~L} \quad \mathrm{LL} \rightarrow \mathrm{CP}$ Left main PA Intraoperative

UL 1) $\mathrm{A}^{1+2 c} \quad$ Pranch $\quad$ Postoperative

$2 \mathrm{~L}$

LL (CP) 2) $\mathrm{A}^{3}$ branch Postoperative

$3 \mathrm{~L}$ UL $\underset{\text { root }}{\mathrm{A}^{3} \text { branch intraoperative }}$

Staple cut-off

4 L UL edge of $\mathrm{A}^{1+2 a}$ Intraoperative branch
Median sternotomy, open heart sac, left main PA injury during left $\mathrm{CP}$

1) On the postoperative 6th day after the lobectomy, hemorrhage from the cut-off part of $\mathrm{A}^{1+2 c}$ branch

2) On the postoperative 3rd day after redo thoracotomy, re-bleeding of the $\mathrm{A}^{3}$ branch due to the rupture of infected vessel

Massive bleeding of A3 root lacerations during upper lobe traction

Gauze-getting caught injury at the staple cut-off end of $\mathrm{A}^{1+2 a}$ branch
With CPB, the proximal site of the injured left main PA was cut in the heart sac

1) Redo thoracotomy, $A^{1+2 c}$ branch was stitched to stop the bleeding

2) Median sternotomy, emergency artificial CPB, the left proximal main PA was cut $\bigcirc \quad$ CPB Survival in the heart sac to save the life by $\mathrm{CP}$

$\mathrm{A}^{3}$ pull-out injury part was pinched with fingers, left main PA was taping with tourniquet tightening, biting with forceps,

Survival $\mathrm{A}^{3}$ pull-out site was sutured

The bleeding site was cut with staple suture

O CPB Survival

Survival 


\section{Continued}

\begin{tabular}{|c|c|c|c|c|c|c|c|c|}
\hline 5 & $\mathrm{~L}$ & UL & ${ }_{\mathrm{A}} 1+2 \mathrm{c}_{\text {branch }}$ & Postoperative & $\begin{array}{l}\text { Injury of }{ }^{A 1+2 c} \text { branch root due to } \\
\text { the traction of upper lobe }\end{array}$ & $\begin{array}{l}\text { Pressure hemostasis and } \\
\text { attaching of the sheet of the } \\
\text { specific biologics }\end{array}$ & & Survival \\
\hline 6 & $\mathrm{~L}$ & UL & $\begin{array}{c}\text { Interlobular } \\
\text { PA }\end{array}$ & Intraoperative & $\begin{array}{l}\text { When forceps was inserted for } \\
\text { interlobular side, interlobular PA } \\
\text { was injured by peeling the severe } \\
\text { adhesion due to chemotherapy }\end{array}$ & $\begin{array}{l}\text { The bleeding was stopped by } \\
\text { attaching of the sheet of } \\
\text { specific biologics }\end{array}$ & & Survival \\
\hline 7 & $\mathrm{~L}$ & LL & ${ }_{A} 88_{\text {branch }}$ & Intraoperative & $\begin{array}{l}\text { Injury of } \mathrm{A}^{8} \text { branch during } \\
\text { detachment of interlobar formation } \\
\text { in the upper and lower lobes }\end{array}$ & $\begin{array}{l}\text { The bleeding was stopped by } \\
\text { attaching of the sheet of } \\
\text { specific biologics }\end{array}$ & & Survival \\
\hline 8 & $\mathrm{R}$ & UL & $\begin{array}{l}\text { Peripheral } \\
\text { interlobular } \\
\text { PA branches }\end{array}$ & Intraoperative & $\begin{array}{l}\text { Injury of interlobular PA branches } \\
\text { while peeling the full tight adhesion } \\
\text { between the chest wall and the } \\
\text { upper lobe apex }\end{array}$ & $\begin{array}{l}\text { Inerlobular artery bleeding in } \\
\text { the upper lobe was stopped by } \\
\text { bulldog forceps and Hemo clip }\end{array}$ & & Survival \\
\hline 9 & $\mathrm{R}$ & $\mathrm{LL}$ & $\begin{array}{l}\mathrm{A}^{6} \text { branch } \\
\text { root }\end{array}$ & Intraoperative & $\begin{array}{l}\text { The tip of thoracoscope collided } \\
\text { with the } \mathrm{A}^{6} \text { branch and injury }\end{array}$ & $\begin{array}{l}\text { Suture hemostasis of } \mathrm{A}^{6} \text { root } \\
\text { laceration and resection of } S^{6} \\
\text { segment }\end{array}$ & $\mathrm{O} \quad \mathrm{CPB}$ & Survival \\
\hline 10 & $\mathrm{R}$ & LL & $\mathrm{A}^{78910}$ branch & Postoperative & $\begin{array}{l}\text { Coming off the silk thread ligature } \\
\text { of } \mathrm{A}^{78910} \text { root after chest closure }\end{array}$ & $\begin{array}{l}\text { After extubation, sudden } \\
\text { massive intrathoracic } \\
\text { hemorrhage, reopening chest, } \\
\text { hemorrhage was found at the } \\
\text { cut end of } \mathrm{A}^{78910} \text { root due to } \\
\text { the detached ligature thread, } \\
\text { the cut-end of } \mathrm{A}^{78910} \text { was } \\
\text { sutured }\end{array}$ & & Survival \\
\hline 11 & $\mathrm{~L}$ & UL & $\mathrm{A}^{3}$ branch & Postoperative & Vascular injury by forceps insertion & $\begin{array}{l}\text { The bleeding was stopped by } \\
\text { attaching of the sheet of } \\
\text { specific biologics }\end{array}$ & & Survival \\
\hline 12 & $\mathrm{~L}$ & LL & $A^{6}$ branch & Intraoperative & $\begin{array}{c}\text { Between the } \mathrm{A}^{6} \text { and } \mathrm{A}^{8910} \text { branches, } \\
\text { vascular injury due to insertion of } \\
\text { staple autosuture }\end{array}$ & $\begin{array}{l}\text { The bleeding was stopped by } \\
\text { attaching of the sheet of } \\
\text { specific biologics }\end{array}$ & & Survival \\
\hline 13 & $\mathrm{R}$ & ML & $\begin{array}{l}\text { Proximal } \\
\text { interlobular } \\
\text { PA }\end{array}$ & Intraoperative & $\begin{array}{l}\text { Adhesion of inflammatory lymph } \\
\text { nodes to the interlobar PA, vascular } \\
\text { injury by peeling with scissors }\end{array}$ & $\begin{array}{l}\text { The bleeding was stopped by } \\
\text { attaching of the sheet of } \\
\text { specific biologics }\end{array}$ & & Survival \\
\hline
\end{tabular}

Bleeding cases were accidental and should be handled with care. Patient age, gender, and clinical background were anonymized and only short-term outcomes were described upon survival and death. L: Left, R: Right, PA: Pulmonary artery, UL: Upper lobectomy, LL: Lower lobectomy, ML: Middle lobectomy, $\mathrm{CP}$ : Completion pneumonectomy, CPB: Cardiopulmonary bypass.

situation at the site of surgery is constantly changing, and the people working there are making "various adjustments according to the situation" rather than "as prescribed".

To improve the quality of surgery, we have to learn from failures and incidents, such as bleeding cases (Safety-I), and developed our skills and practice of surgical safety management.

In order to form a system to support surgical safety, we looked back on our experience in dealing with bleeding cases and developed a method to apply a new approach (Safety-II) called resilient healthcare assuming a complex system to surgery. 
Table 3. Features and Differences of Safety-I and Safety-II.

\begin{tabular}{|c|c|c|}
\hline & Safety-I & Safety-II \\
\hline Features of the approach & Analytic approach & Synthetic approach \\
\hline Definition of safety & The number of failures is small enough to be demanded & The number of successes is as high as possible \\
\hline \multirow[t]{2}{*}{$\begin{array}{l}\text { Purpose and type of safety } \\
\text { management }\end{array}$} & - Prevent things from going wrong & $\begin{array}{l}\text { - Make things work well under fluctuations and } \\
\text { constraints }\end{array}$ \\
\hline & - Reactive safety management & - Advanced safety management \\
\hline Target of learning & Learn from failure cases & Learn from daily practice \\
\hline \multirow[t]{2}{*}{$\begin{array}{l}\text { How to understand the system to } \\
\text { handle }\end{array}$} & - Static system without change (static system) & $\begin{array}{l}\text { Dynamic system that keeps changing from } \\
\text { moment to moment (dynamic system) }\end{array}$ \\
\hline & - Easy-to-use system (tractable system) & - Cumbersome system (intractable system) \\
\hline How to perceive failure and success & The path of failure and success is different & Failure and success happen in the same way \\
\hline $\begin{array}{l}\text { Relationship between process and } \\
\text { result }\end{array}$ & Linear model (causal relationship) & Non-linear model (interaction and feedback) \\
\hline Human position in safety & Humans work negatively for safety and are a risk factor & $\begin{array}{l}\text { Humans are essential to the safety and flexibility } \\
\text { of the system }\end{array}$ \\
\hline $\begin{array}{l}\text { How to perceive performance } \\
\text { fluctuations }\end{array}$ & Harmful and should be removed as much as possible & Irreversible, useful, monitored and managed \\
\hline \multirow[t]{2}{*}{ Points of interest } & - What (event) happened & $\begin{array}{l}\text { - What (phenomenon) is occurring in the } \\
\text { behavior of the entire system }\end{array}$ \\
\hline & - Why it happened & - How it happens (interaction) \\
\hline
\end{tabular}

Safety-I recognizes the limitations of Safety-II and has evolved from a critical standpoint. However, Safety-I and Safety-II are complementary to each other, and safety management of social technology systems also requires therapy, and Safety-II is not a substitute for Safety-I. This table is quoted in English from the book that Professor Kazue Nakajima authored. (Introduction to Resilient Health Care. Ability to respond flexibly with disturbances and constraints) (Japanese), Igakushoin, ISBN976-4-26-02828-8, page 14, 2019) [9].

\section{Results}

\subsection{Outcome of the Medical Accident Information Collection Project Database}

Table 1 shows the case details of the bleeding accidents $(n=25)$ searched in the medical accident information collection project database. Bleeding cases were accidental and should be handled with care. Patient age, gender, and clinical background were anonymized and only short-term outcomes were described about survival and death. Table 4 shows the summary of the bleeding accidents from Table 1. Regarding the surgical sites, the left side (68\%) was common. Regarding the procedure, the upper lobectomy cases (56\%) were commonly observed. Regarding the sites of bleeding, there were the pulmonary artery (56\%), the pulmonary vein $(12 \%)$, and the aorta $(12 \%)$. Bleeding was observed in the intraoperative (76\%) and postoperative periods (20\%).

The causes of bleeding included damage of adhesion detachment, damage of automatic suture insertion, detachment of ultrasonic scalpel, damage during vascular taping, damage when forceps are inserted, when vascular forceps are applied, when the resected lung is removed, lymph node dissection, exfoliation of the infiltrated adventitia of the pulmonary artery, and when one lung ventilation is released. 
Table 4. The summary of the bleeding accidents $(n=25)$ from the database of the Project to Collect Medical Near-Miss/Adverse Event Information.

\begin{tabular}{|c|c|c|c|}
\hline Analysis items & Breakdown & $\mathrm{n}=25$ & $(\%)$ \\
\hline \multirow[t]{9}{*}{ Surgical sites } & Left & 17 & 68 \\
\hline & Upper lobe & 9 & 36 \\
\hline & Lower lobe & 3 & 12 \\
\hline & Pneumonectomy & 2 & 8 \\
\hline & S3 & 2 & 8 \\
\hline & Unknown & 1 & 4 \\
\hline & Right & 8 & 32 \\
\hline & Upper lobe & 5 & 20 \\
\hline & Lower lobe & 3 & 12 \\
\hline \multirow[t]{7}{*}{ Procedures } & Left upper lobectomy & 9 & 36 \\
\hline & Left lower lobectomy & 3 & 12 \\
\hline & Left pneumonectomy & 2 & 8 \\
\hline & Right upper lobectomy & 5 & 20 \\
\hline & Right lower lobectomy & 3 & 12 \\
\hline & S3-segmentectomy & 2 & 8 \\
\hline & Unknown & 1 & 4 \\
\hline \multirow[t]{3}{*}{ Sites of bleeding } & Pulmonary artery & 14 & 56 \\
\hline & Pulmonary vein & 3 & 12 \\
\hline & Right atrium & 1 & 4 \\
\hline \multirow[t]{3}{*}{ Right heart veins } & & 1 & 4 \\
\hline & Aorta & 3 & 12 \\
\hline & Unknown & 3 & 12 \\
\hline \multirow[t]{3}{*}{ Perioperative period } & Intraoperative & 19 & 76 \\
\hline & Postoperative & 5 & 20 \\
\hline & Unknown & 1 & 4 \\
\hline \multirow[t]{2}{*}{ Circulation auxiliary equipment } & Percutaneous Cardiopulmonary System & 3 & 12 \\
\hline & Cardiopulmonary Bypass & 5 & 20 \\
\hline \multirow[t]{2}{*}{ Support by cardiovascular surgeon } & Supported & 9 & 36 \\
\hline & No support & 16 & 64 \\
\hline Pneumonectomy for life-saving & & 4 & 16 \\
\hline Death & & 9 & 36 \\
\hline
\end{tabular}

The circulation auxiliary equipment was required in 8 cases (32\%), the breakdown was 5 cases of "cardiopulmonary bypass" (20\%), and 3 cases of "percutaneous cardiopulmonary system" (12\%). There were 9 cases of the support by the cardiovascular surgeon (36\%). 
The corresponding procedures included suture stasis and total resection, that is, there were 4 cases of a pneumonectomy for life-saving (16\%), that was a change in procedure, and 9 cases (36\%) involved death.

Thoracic surgery is a very high-risk operation that can lead to life-threatening conditions that can lead to increased bleeding and death if the procedure or operation is incorrect. We can learn about various types of bleeding events and apply these findings to normal routine surgery. It is important to learn, prepare and have a large repertoire.

\subsection{Outcome of the Incident in Our Department.}

Table 2 shows the case details of our experience $(n=13)$ searched in our database. Bleeding cases were accidental and should be handled with care. Patient age, gender, and clinical background were anonymized and only short-term outcomes were described regarding survival and death. Table 5 shows a summary of the bleeding accidents from Table 2. Regarding the surgical sites, the left side (62.9\%) was common. About the procedure, the upper lobectomy cases (53.8\%) were commonly observed. Regarding the sites of bleeding, it was the pulmonary artery (100\%). The bleeding was observed in the intraoperative

Table 5. The summary of the bleeding accidents $(n=13)$ in our department.

\begin{tabular}{|c|c|c|c|}
\hline Analysis items & Breakdown & $\mathrm{n}=13$ & $(\%)$ \\
\hline \multirow[t]{7}{*}{ Surgical sites } & Left & 9 & 62.9 \\
\hline & Upper lobe & 6 & 46.2 \\
\hline & Lower lobe & 3 & 23.1 \\
\hline & Right & 4 & 30.8 \\
\hline & Upper lobe & 1 & 7.7 \\
\hline & Middle Lobe & 1 & 7.7 \\
\hline & Lower Lobe & 2 & 14.3 \\
\hline \multirow[t]{5}{*}{ Procedures } & Left upper lobectomy & 7 & 53.8 \\
\hline & Left lower lobectomy & 2 & 15.4 \\
\hline & Right upper lobectomy & 1 & 7.7 \\
\hline & Right middle lobectomy & 1 & 7.7 \\
\hline & Right lower lobectomy & 2 & 15.4 \\
\hline Sites of bleeding & Pulmonary artery & 13 & 100 \\
\hline \multirow[t]{2}{*}{ Perioperative period } & Intraoperative & 11 & 84.6 \\
\hline & Postoperative & 2 & 15.4 \\
\hline Circulation auxiliary equipment & Cardiopulmonary Bypass & 3 & 23.1 \\
\hline \multirow[t]{2}{*}{ Support by cardiovascular surgeon } & Supported & 3 & 23.1 \\
\hline & No support & 10 & 76.9 \\
\hline Pneumonectomy for life-saving & & 1 & 7.7 \\
\hline Death & & 0 & 0 \\
\hline
\end{tabular}


(84.6\%) and postoperative periods (15.4\%).

The causes of bleeding included injury of adhesion peeling operation, pull-out injury during lung traction, injury due to forceps insertion, gauze attachment with staple line, thoracoscopic collision, infectious vascular rupture, detachment of vascular ligature, removal of automatic suture, and suction tube hit and sucking of the transected end.

These cases were observed within or outside the expected range. The circulation auxiliary equipment was required in 3 cases (21.4\%), i.e., the breakdown was 3 cases of "cardiopulmonary bypass" (21.4\%). There were 3 cases of support by the cardiovascular surgeon (23.1\%).

The corresponding procedures included suture stasis and total resection, that is, there was 1 case of pneumonectomy for life-saving (7.7\%), which was a change in procedure, and there were no deaths.

For the life-threatening conditions, we avoided a patient's death by changing the surgical procedure from a lobectomy to pneumonectomy, and with the cooperation of the cardiovascular surgeons with multi-professional experience and the formation and cooperation of highly-reliability surgical teams in the hospital organizations. We could do it and learn the practical experience. It was a successful case by implementation of resilient healthcare and a balanced combination of Safety-I and Safety-II. By learning from the successful cases, that is, the bleeding can be stopped or life can be saved by appropriate measures, that is, the successful cases. Crisis response and management methods can be surely practiced in the event of a life crisis.

\subsection{Implementation of Resilient Surgical Healthcare Theory for a System to Support Surgical Safety (Safety-I and Safety-II)}

The conventional safety management method (Safety-I) of "learning from failure, identifying the cause, and taking measures to prevent recurrence" is premised on the linear system industry, such as automobile production lines, and is complex like as medical care. It has been pointed out that there is a limit to its usefulness in systems (complex systems).

Against this criticism, resilience engineering theory said, "Because success and failure have the same origin in complex systems, we focused on what was done well, not failure, and predicted the future without waiting for an accident. Take the opposite approach of the conventional safety management method of "corresponding to the target" (Safety-II).

With the knowledge and coping strategies for thoracic surgery incidents and accidents revealed, we divided them into four surgical situations and considered surgical safety in the practice of resilient healthcare: 3.3.1. daily routine work in normal surgery, 3.3.2. unusual patient's individual factors, 3.3.3. massive bleeding, and 3.3.4. unusual crisis of the unexpected major bleeding.

\subsubsection{In the Case of Daily Routine Work in Normal Surgery}

The pulmonary artery can be easily detached and dissected. As a typical com- 
mon adjustment, Safety-I is essential as follows.

1) Safely exfoliate and expose blood vessels.

2) Taping to ensure the safety of blood vessels.

3) Safe insertion of automatic suture device.

4) Safe dissection by automatic suture device.

5) Safe removal of automatic suture device.

If the pulmonary artery is damaged and injured (bleeding), hemostasis is usually performed according to the damaged site (expected within the expected range).

\subsubsection{In the Case of Unusual Patient's Individual Factors}

For example, the pulmonary artery can be difficult to be detached and dissected due to inflammation and cancer invasion.

We need finer adjustments with the combination of Safety-I and Safety-II.

1) Safer peeling and exposure of blood vessels (as a bleeding measure, foresee bleeding and taping).

2) If the surrounding tissue has inflammatory adhesions, the vulnerable wall is fragile, and the vascular wall of the elderly is thin.

3) Abnormalities of unusual blood vessel running and anatomical abnormalities.

4) Due to cancer infiltration.

5) Poor physical condition of surgeons, such as lack of sleep, stress, rush, and no time to spare.

6) The operation should be performed slowly, accurately, widely and carefully.

If the pulmonary artery is injured (bleeding), hemostasis is performed according to the damaged site (unexpected within the expected range).

\subsubsection{In the Case of Massive Bleeding}

The surgeon must anticipate migration to the life-threatening bleeding.

We need the finest adjustments with the well-balanced combination of Safety-I and Safety-II. A resilient response is performed to the degree of the patient's crisis shock vitals.

1) Small bleeding from a small artery and venous vessels. The bleeding volume is estimated at less than $500 \mathrm{ml}$. This situation is a normal bleeding event, which is controllable.

The surgeon's personal technical skills and non-technical skills are dependent on personal knowledge, experience and surgical technique (variation of compression method and suturing method).

2) Moderate bleeding from a moderate artery vessel such as the pulmonary artery branch. The bleeding volume is estimated between $500 \mathrm{ml}-1000 \mathrm{ml}$ or more.

If the bleeding can be controllable, it is OK. If not controllable, it becomes uncertain, which may lead to severe bleeding.

Surgeons must work as a team, not as individuals, with technical and 
non-technical skills (surgeon's knowledge, experience, expert skills, teamwork, selection and decision-making of optimal hemostasis methods, implementation, prediction and preventive measures for severe extended bleeding).

3) Severe bleeding from large blood vessels such as the aorta, main pulmonary artery, and great venous vessels. The bleeding volume is over $1000 \mathrm{ml}$.

If there is unexpected major bleeding, an emergency response is required in the event of a crisis.

Surgeons respond to massive hemorrhage by mobilizing all surgical technical and non-technical skills of all the surgical department organizations.

The surgical team consists of an anesthesiologist, scrub nurse, circulating nurse, cardiovascular surgeon, clinical engineer, and intensive care unit staff. Teamwork, leadership and followership, and technical and non-technical skills are mobilized.

\subsubsection{In the Case of Unusual Crisis of the Unexpected Major Bleeding}

The operating room team consists of multi-professionals and requires a resilient response with a finer and well-balanced combination of Safety-I and Safety-II. Each occupation shares roles and cooperates.

The surgeon is to stop bleeding, aspirate blood, remove hematoma, and identify bleeding sites on the vessel wall. Stopping the bleeding is attempted by compression with lung tissue, forceps, gauze, cotton ball, etc. Enlarging the open chest for a wider field of view and better operation. Press and place with a hemostatic sheet. Secure the central and peripheral sides of the bleeding site, block and suture. Recovery from bleeding, and avoidance of rebleeding.

The anesthesiologist is to keep the patient's breathing and circulation normal. Maintaining vitals, knowing the bleeding volume, preparing for blood transfusion, performing blood transfusion, and requesting support from another anesthesiologist.

The operating room nurse is to make an emergency call, and assist with surgical instruments. Also, they prepare for a blood transfusion, and provide an accurate gauze count.

To improve the resilience ability of our surgical team, to monitor bleeding amounts and respond to hemorrhage and saving the lives of our patients are our surgical goals.

\section{Discussion}

The incidence of pulmonary artery bleeding reported by a large-volume by very experienced surgeons and centers is very low [25]-[32]. The incidence of conversion to a thoracotomy because of bleeding, which is likely from the pulmonary artery in most cases, ranges from $0.5 \%$ to $5.2 \%$. In addition, the reports of an intraoperative catastrophe, such as death, caused by uncontrolled pulmonary artery bleeding in a high-volume series are negligible.

Mild bleeding is usually not a troublesome problem and can typically be easily solved. Some biological materials can be used to stop bleeding as previously 
mentioned in the literature [16] [33]. However, Xiao ZL et al. [20] used the electrocoagulation hook or Harmonic scalpel to achieve an exact hemostasis. Titanium or automatic clip applier clips may also be used to stop bleeding from some visible small blood vessels.

The significant reason that a video-assisted thoracic surgery (VATS) approach is not used more often could be concerned that the ability to safety control and dissect the hilar pulmonary vessels is limited [34]. Not all, but some surgeons may not feel comfortable visualizing and handling these structures through a small incision and a scope while watching on monitor. In particular, concerns over how to control and repair any inadvertent vascular injury are likely very prominent for many surgeons [34]. Of the pulmonary structures, pulmonary artery bleeding caused by injury during dissection of the lymph nodes and manipulation of forceps and vessels is generally the most feared because of the relatively delicate nature of the vessel and very-high volume of blood flow through this structure. Compared to the other hilar pulmonary structures such as the pulmonary vein, it is generally thought that the pulmonary artery is most easily injured [34]. Importantly, attempts to repair a pulmonary artery injury can sometimes lead to more extensive tearing that could potentially progress to involve the proximal main pulmonary arterial direction [34]. Major pulmonary artery injuries can result in an intraoperative patient death caused by massive blood loss when the injury is not adequately controlled in a timely fashion. Perhaps not as immediately catastrophic but also potentially devastating to patients, a pulmonary artery injury could lead to the need to perform a more extensive pulmonary resection, such as a pneumonectomy, rather than the planned lobectomy. We had experienced such cases $(n=3)$ in Table 5 and could fortunately save the patient's life by the support of cardiovascular surgeons and a cardiopulmonary bypass.

In the next section, we discuss the response and treatment for the two types of bleeding by dividing normal and massive critical situations.

\subsection{Response and Treatment Methods for the Usual Controllable Bleeding}

The bleeding of the pulmonary artery branch is performed using the lung tissue itself, gauze, cotton compression, attaching a sheet of hemostatic tissue adhesion, and suturing the blood vessels. In the first place, it is important to prevent bleeding, and to avoid bleeding.

Based on the protective manipulation of the blood vessels, intravascular sheath detachment is recommended. Although a safe detachment, detachment with force control without tension on the fragile pulmonary artery wall is fundamentally an important operation. The foresight of peripheral branching of blood vessels at the time of exfoliation is to expose the branch vessels, lung grasping method for expanding visual field, and direction of counter traction. The balance between gender and power is important, and prevention of pulmonary artery intimal detachment and withdrawal of blood vessel roots is important. 
Surgeons have to learn how to dissect blood vessels with infiltration and inflammatory adhesions. Bleedings of the $\mathrm{A}^{3}$ and $\mathrm{A}^{1+2}$ branches in the upper lobes are a higher risk than the bleedings of the lower lobes $A^{6}$ and $A^{78910}$ branches, because the difficulty of repair is high, and emergency simulation becomes important. Depending on whether the site of bleeding of the pulmonary artery has to be resected or not, the flexibility of the hemostatic operation method changes.

From the viewpoint of patient safety, bleeding events must be learned from the standpoint of the surgeon, assistants, supervising physician, and training physician. As the total strength of the surgery team, everyday intraoperative communication becomes very important, for example, an easy-to-speak atmosphere, that is, non-technical skills resilience, and resilience ability for unexpected accidents. We have to consider the range of possible bleeding treatments based on the presence of inflammatory adhesions, a history of thoracotomy, post-chemoradiation, and the presence of a cardiovascular team.

\subsection{Response and Treatment Methods for the Unexpected and Uncontrollable Bleeding}

In the case of unexpected, uncontrollable, massive bleeding, or life-threatening bleeding that is not controllable, the following items should be noted. It is necessary to simulate in advance from the usual.

1) To check and stabilize the vitality in cooperation with the anesthesiologist and surrounding nurse.

2) Confirmation of the bleeding point and compression of bleeding site because the bleeding from the upper lobe pulmonary artery increased the fatal risk. This will reduce the amount of bleeding and prevent secondary disasters (increased vascular damage).

3) To prioritize hemostasis (compression), add the thoracotomy, secure the intrathoracic visual field, remove massive hematomas, peel off, secure and taping of the main trunk of the pulmonary artery, superior pulmonary vein and inferior pulmonary vein.

4) Do not release the pressure on the bleeding site, check the bleeding area, or proceed with recovery of the patient's vitals until the blood transfusion is secured and the blood transfusion occurs.

5) To consider the option to change to a life-saving procedure such as a pneumonectomy.

6) To consider support from a cardiovascular surgeon and prepare for a cardiopulmonary bypass.

7) Efforts should be made to understand blood loss, check the amount of blood transfusion, minimize blood loss, and pump blood during the transfusion to maintain the patient's vitals.

8) After preparation, remove massive hematoma, release compression of the bleeding, taking into account the determination of damage, the size of the lesion, consider the amount of blood transfusion, consider the hemostasis methods and blood vessel repair methods. 
9) Explanation to patient's family, report to the department of patient safety management, and act as a hospital organization.

10) Efforts to improve the surgical technical skills (vascular suture method) of the surgical procedure from normal times.

11) Simulation during critical bleeding.

12) Non-technical skills during crisis (situation awareness, decision making, leadership and followership, communication, and stress relief) are important.

We must be aware of organizing the surgical team and operating room team from the usual one.

In order to simulate in a crisis situation and to demonstrate the resilience of the surgical team, all the teams can perform non-technical skills.

\subsection{Performance Fluctuations in the Stability of the Operating Team for Thoracic Surgery}

Figure 3 shows a general model for the performance fluctuations in the stability of the operating team by responding to disturbances in thoracic surgery. The vertical axis represents the stability and performance, and the horizontal axis represents the time course of the surgery. In the case of lung cancer surgery, a lobectomy is performed, there are three important scenes, that is, dissection of the pulmonary artery, pulmonary vein, and lobular bronchus. However, a surgeon sometimes encounters unexpected situations, such as adhesion and vascular bleeding events, which means disturbances in the normal surgical course.

These disturbances are well responded by the individuals, operating team, and hospital organization. Compared to the normal flow, it consumes a lot of time and performance drops during the overall course of surgery. The surgical team becomes less stable and unstable.

In the event of a life-threatening massive bleeding, the surgeon responds with an operating room staff team or hospital organization to prepare and administer blood transfusions, or with the help of a cardiovascular surgeon, save lives using a heart-lung machine and the bleeding site. The surgeon repairs the hemorrhage and the anesthesiologist stabilizes the hemodynamics. The patient's life is then maintained, recovered, and successfully saved.

Depending on the magnitude and situation of the disturbance, the performance of the surgical team will fluctuate and the stability will change. It is Safety-II that changes the performance of the surgical team according to the disturbance, stabilizes the place, and allows life to continue.

\subsection{Reconcile Work-As-Imagined (WAI) and Work-As-Done (WAD) in Surgery}

Figure 4 shows the reconciling Work-As-Imagined (WAI: How to do the work that you think in your head) and Work-As-Done (WAD: How the actual work is done) in Surgery. In surgery, the WAI is manual and the surgical procedure plan.

Surgery is performed according to preoperative complications, the WAD is 


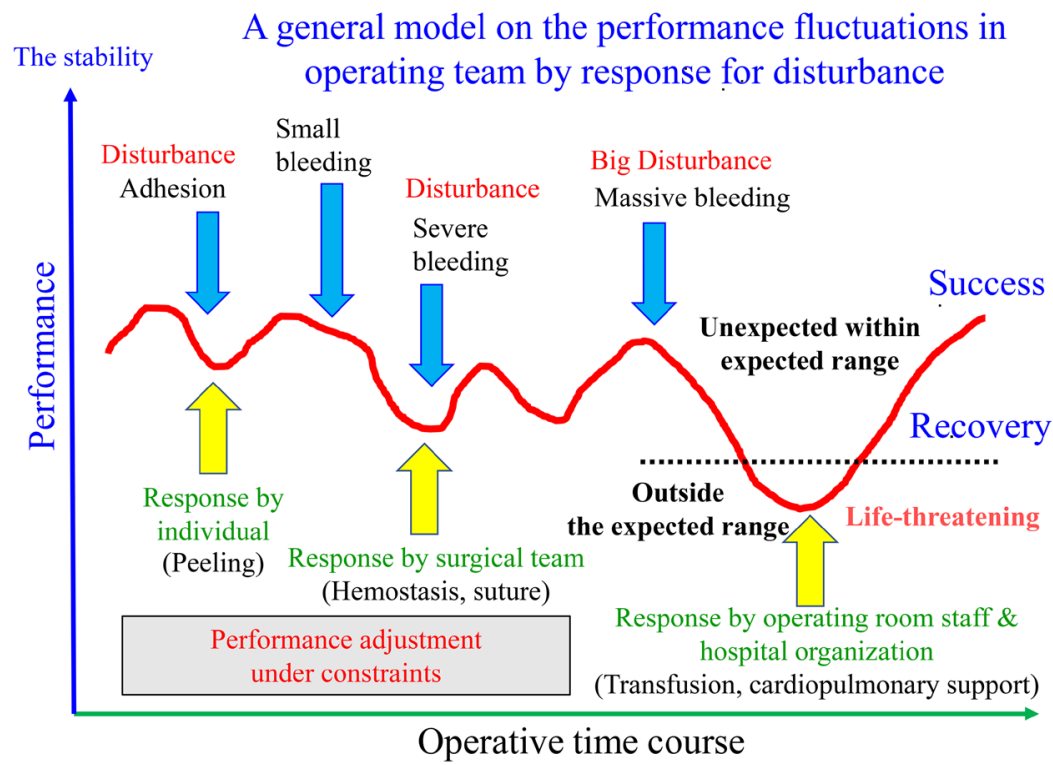

Figure 3. The change in surgical performances during the operative time course. Figure shows a general model of performance fluctuations in the stability of the operating team responding to disturbances. The vertical axis represents the stability and performance, and the horizontal axis represents the time course of surgery. In the case of lung cancer surgery, a lobectomy is performed, there are three important areas, that is, dissection of the pulmonary artery, pulmonary vein, and lobular bronchus. However, a surgeon sometimes encounters unexpected situations, such as adhesion and vascular bleeding events, which means disturbances in the normal surgical course. These disturbances are well responded by individuals, the operating team, and hospital organization. Compared to the normal flow, it consumes a lot of time and performance drops during the overall course of surgery. The surgical team becomes less stable. In the event of a life-threatening massive bleeding, the surgeon responds with an operating room staff team or hospital organization to prepare and administer blood transfusions, or with the help of a cardiovascular surgeon, save lives with a cardiopulmonary bypass for the bleeding site. The surgeon repairs the hemorrhage and the anesthesiologist stabilizes the hemodynamics. The patient's life is maintained, recovered, and successfully saved. Depending on the magnitude and situation of the disturbance, the performance of the surgical team will fluctuate and the stability will change. It is Safety-II that changes the performance of the surgical team according to the disturbance, stabilizes the place, and the patient lives.

the actual surgery, that is, the demonstration of surgical practice. However, in reality, the results of surgery appear as surgical outcomes due to time and member constraints and disturbances such as major bleeding. Surgical outcomes are recorded and evaluated in texts, pictures, photographs, videos, etc. These valuable experiences will be shared at team conferences to reflect, learn and improve, which are stored as a large "repertoire". The surgeons' feedback for the next surgery is to improve technical skills. It is important to reconcile the WAI and WAD in surgery.

\subsection{A System to Support Surgical Safety Based on Resilient Healthcare Theory}

Figure 5 shows a system to support surgical safety and implementation of the 


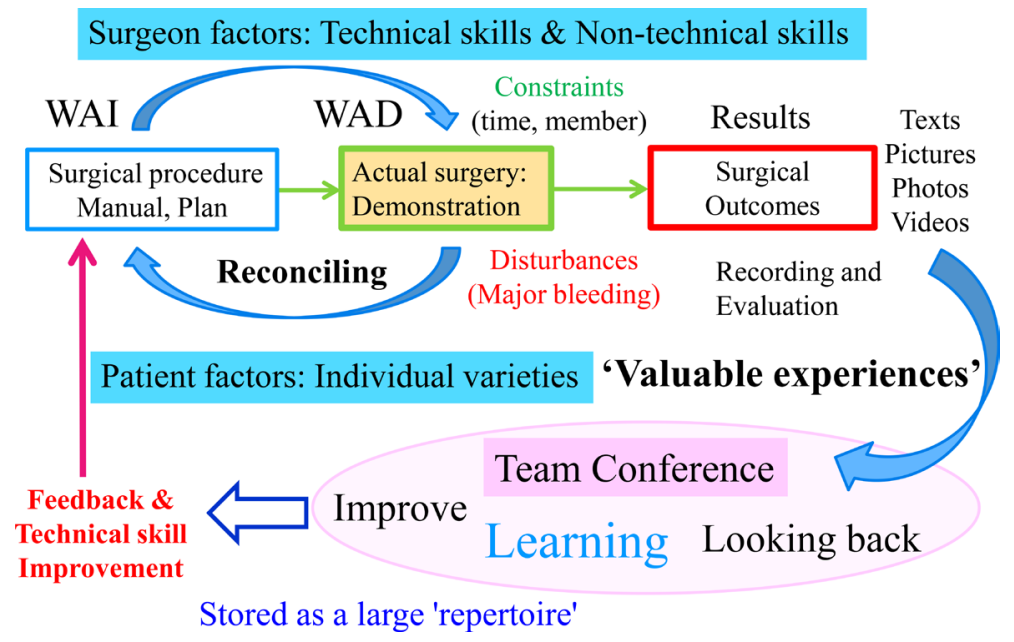

Figure 4. Reconcile Work-As-Imagined (WAI) and Work-As-Done (WAD) in surgery. In surgery, work-as-imagined (WAI: "How to do the work that you think in your head") is manual and plan of surgical procedure. Surgery is performed according to preoperative complications, work-as-done (WAD: "How the actual work is done") is an actual surgery, that is, demonstration of surgical practice. However, in reality, the results of surgery appear as surgical outcomes due to time and member constraints and disturbances such as major bleeding. Surgical outcomes are recorded and evaluated in texts, pictures, photographs, videos, etc. These valuable experiences will be shared at team conferences to reflect, learn and improve, which are stored as a large "repertoire". Surgeons provide feedback to the next surgery to improve technical skills.

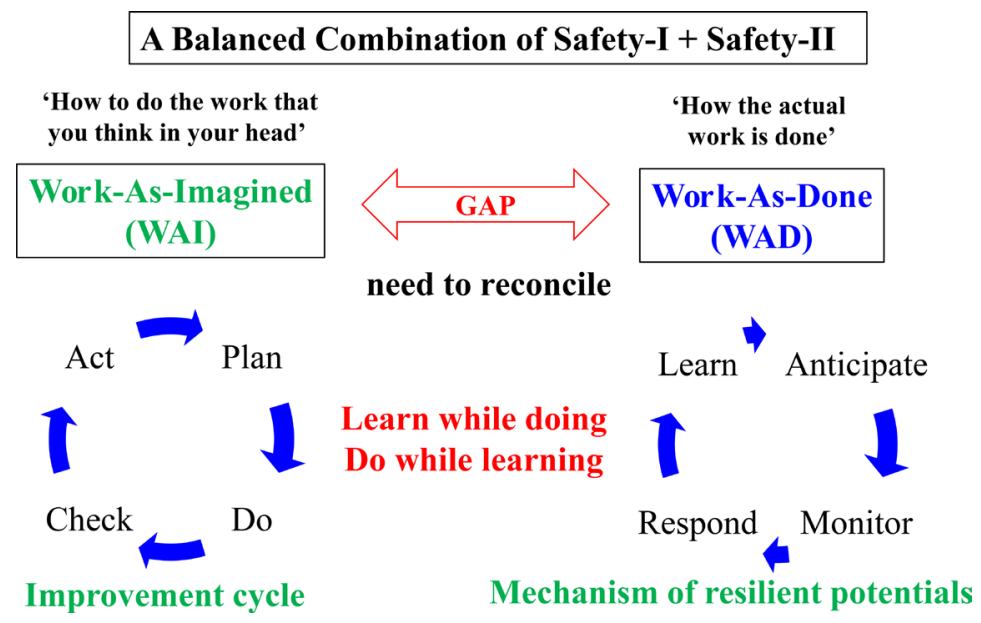

Figure 5. A System to Support Surgical Safety based on Resilient Healthcare Theory. A balanced combination of Safety-I and Safety-II is important for building a system to support surgical safety. Work-As-Imagined (WAI) is how to do the work that you think in your head. Work-As-Done (WAD) is how the actual work is done. There is a gap between the WAI and WAD, which needs to be reconciled. By using the PDCA cycle (plan, do, check, and act), the quality of surgery improves. For resilience healthcare, it is important to go through a mechanism of anticipating, monitoring, responding and learning. By increasing these four potentials, that is, resilience abilities will improve, but for this purpose, it is important to do it while learning and to learn while doing.

resilient healthcare theory. A balanced combination of Safety-I and Safety-II is important for building a system that supports surgical safety. Work-As-Imagined 
(WAI) is "how to do the work that you think in your head". Work-As-Done (WAD) is "how the actual work is done". There is a gap between the WAI and WAD, which needs to be reconciled. By using the PDCA cycle (plan, do, check, and act), the quality of surgery improves.

For implementation of the resilience healthcare theory in surgery, it is important to go through a mechanism of anticipating, monitoring, responding and learning. By increasing these four potentials, the ability of resilience healthcare will improve, but for this purpose, it is important to do it while learning and to learn while doing.

Lastly, in order to reduce the number of surgical bleeding incidents, the following items are important.

1) We have to know the many variations of bleeding cases that we have experienced and learned.

2) We should know how to deal with various bleeding cases, and regularly practice so that we can practice successful methods.

3) During surgery, it is important to predict that bleeding may occur at any time.

4) We should monitor the operative situation at the time of bleeding and the response.

5) We should know performance fluctuations during the operative time course due to various disturbances.

6) We have to adjust the various disturbances under constraints and stabilize the operative field.

To learn bleeding cases that we had responded well in the past and to build it as a system to support surgical safety, for that purpose, reconciling the WAI and WAD in the practice of surgical resilient healthcare, from the perspective of Safety-I and Safety-II, it is important to consider surgical patient safety measures.

\section{Conclusions}

Since bleeding cases are infrequent and inexperienced; we always try to proceed with surgery assuming a crisis situation, adhere to routine procedures and its standardization.

It is important to do it, that is, to practice safely, to learn from bleeding cases, and to look back and inherit.

We can practice Safety-I and Safety-II and implement the surgical resilience healthcare system (mechanism of anticipating, monitoring, responding, and learning). We can flexibly respond to the unexpected bleeding disturbances under constraints by adjusting the surgeon individuals, surgical team, and hospital organization.

\section{Acknowledgements}

This study was supported by JSPS KAKENHI Grant Number JP18K04636 and 
by a Grant-in-Aid for Clinical Research from Miyazaki University Hospital and approved by the University of Miyazaki Hospital Clinical Research Ethics Board (No. O-0736 and No. O-0737) in June 2020.

\section{Conflicts of Interest}

The authors declare no conflicts of interest regarding the publication of this paper.

\section{References}

[1] Holnagel, E. (2014) Safety I and Safety II: The Past and Future of Safety Management. Ashgate, Farnham.

[2] Hollnagel, E. and Braithwaite, J. (2013) Resilient Health Care (Ashgate Studies in Resilience Engineering). CRC Press, Boca Raton.

[3] Hollnagel, E., Paries, J. and Wreathall, J. (2013) Resilience Engineering in Practice: A Guidebook (Ashgate Studies in Resilience Engineering). CRC Press, Boca Raton.

[4] Hollnagel, E., Braithwaite, J. and Wears, R.L. (2018) Delivering Resilient Health Care. Routledge, Abingdon-on-Thames. https://doi.org/10.4324/9780429469695

[5] Braithwaite, J., Wears, R.L. and Hollnagel, E. (2019) Resilient Health Care, Volume 3: Reconciling Work-as-Imagined and Work-as-Done. CRC Press, Boca Raton.

[6] Wears, R.L. and Hollnagel, E. (2015) Resilient Health Care, Volume 2: The Resilience of Everyday Clinical Work (Ashgate Studies in Resilience Engineering). CRC Press, Boca Raton.

[7] Woods, D.D. and Hollnagel, E. (2006) Resilience Engineering: Concepts and Precepts. CRC Press, Boca Raton.

[8] Nemeth, C.P. and Hollnagel, E. (2014) Resilience Engineering in Practice, Volume 2: Becoming Resilient (Ashgate Studies in Resilience Engineering). CRC Press, Boca Raton.

[9] Nakajima, K. (2019) Introduction to Resilient Health Care. Ability to Respond Flexibly with Disturbances and Constraints. Igakushoin, Tokyo, 14. (In Japanese)

[10] Ayabe, T., Tomita, M., Okumura, M., Shimizu, S., Uchida, E., Miura, Y., Itai, K. and Nakamura, K. (2018) Evaluation and Outcomes of Multidisciplinary-Reported Incidents Regarding Patient Safety Management at Special Functioning Hospital in Japan. Open Journal of Safety Science and Technology, 8, 107-136. https://doi.org/10.4236/ojsst.2018.84007

[11] Ayabe, T., Shinpuku, G., Tomita, M., Nakamura, S., Yokoyama, E., Shimizu, S., Okumura, M., Itai, K., Tsuneyoshi, I., Takeshima, H. and Nakamura, K. (2017) Changes in Safety Attitude and Improvement of Multidisciplinary Teamwork by Implementation of the WHO Surgical Safety Checklist in University Hospital. Open Journal of Safety Science and Technology, 7, 22-41. https://doi.org/10.4236/ojsst.2017.71003

[12] Ayabe, T., Tomita, M., Okumura, M., Maeda, R. and Nakamura, K. (2018) Evaluation and Outcome of Surgeon-Reported Incidents Regarding Surgical Patient Safety. Surgical Science, 9, 422-445. https://doi.org/10.4236/ss.2018.911049

[13] Ayabe, T., Tomita, M., Maeda, R., Okumura, M., Nakamura, K. and Nakajima, K. (2020) Implementation of Resilience Engineering for Thoracic Surgery. Reconciling Work-as-Imagined and Work-as-Done. Surgical Science, 11, 257-273. https://doi.org/10.4236/ss.2020.119028 
[14] Ayabe, T., Tomita, M., Maeda, R., Okumura, M., Nakamura, K., Nakajima, S. and Nakajima, K. (2020) Implementation of Resilience Engineering for Operating Room. Unveiling the Hidden Interactions among Multi-Professionals in a Surgical Team. Surgical Science, 11, 242-256. https://doi.org/10.4236/ss.2020.119027

[15] Masuda, M., Kuwano, H., Okumura, M., Amano, J., Arai, H., Endo, S., Doki, Y., Kobayashi, J., Motomura, N., Nishida, H., Saiki, Y., Tanaka, F., Tanemoto, K., Toh, Y., Yokomise, H., Committee for Scientific Affairs and The Japanese Association for Thoracic Surgery (2012) Thoracic and Cardiovascular Surgery in Japan during 2012: Annual Report by the Japanese Association for Thoracic Surgery. General Thoracic and Cardiovascular Surgery, 62, 734-764.

https://doi.org/10.1007/s11748-014-0464-0

[16] Yamashita, S., Tokuishi, K., Moroga, T., Abe, S., Yamamoto, K., Miyahara, S., Yoshida, Y., Yanagisawa, J., Hamatake, D., Hiratsuka, M., Yoshinaga, Y., Yamamoto, S., Shiraishi, T., Kawahara, K. and Iwasakai, A. (2013) Totally Thoracoscopic Surgery and Troubleshooting for Bleeding in Non-Small Cell Lung Cancer. The Annals of Thoracic Surgery, 95, 994-999. https://doi.org/10.1016/j.athoracsur.2012.11.005

[17] Mei, J., Pu, Q., Liao, H., Ma, L., Zhu, Y. and Liu, L. (2013) A Novel Method for Troubleshooting Vascular Injury during Anatomic Thoracoscopic Pulmonary Resection without Conversion to Thoracotomy. Surgical Endoscopy, 27, 530-537. https://doi.org/10.1007/s00464-012-2475-1

[18] Yano, M., Takao, M., Fujinaga, T., Arimura, T., Fukai, I., Ota, S., Saito, Y. and Okuda, K. (2013) Adverse Events of Pulmonary Vascular Stapling in Thoracic Surgery. Interactive Cardio Vascular and Thoracic Surgery, 17, 280-284. https://doi.org/10.1093/icvts/ivt130

[19] Flores, R.M., Ihekweazu, U., Dycoco, J., Rizk, N.P.,, Rusch, V.W., Bains, M.S., Downey, R.J., Finley, D., Adusumilli, P., Sarkaria, I., Huang, J. and Park, B. (2011) Video-Assisted Thoracoscopic Surgery (VATS) Lobectomy: Catastrophic Intraoperative Complications. The Journal of Thoracic and Cardiovascular Surgery, 142, 1412-1417. https://doi.org/10.1016/j.jtcvs.2011.09.028

[20] Xiao, Z.L., Mei, J.D., Pu, Q. and Liu, L.X. (2014) Technical Strategy for Dealing with Bleeding during Thoracoscopic Lung Surgery. Annals of Cardiothoracic Surgery, 3, 213-215.

[21] Dunning, J. and Walker, W.S. (2012) Pulmonary Artery Bleeding Caused during VATS Lobectomy. Annals of Cardiothoracic Surgery, 1, 109-110.

[22] Sawada, S., Komori, E. and Yamashita, M. (2009) Evaluation of Video-Assisted Thoracoscopic Surgery Lobectomy Requiring Emergency Conversion to Thoracotomy. European Journal of Cardio-Thoracic Surgery, 36, 487-490. https://doi.org/10.1016/j.ejcts.2009.04.004

[23] Miyazaki, T., Yamasaki, N., Tsuchiya, T., Matsumoto, K., Hatachi, G., Kitamura, Y., Obata, T., Doi, R., Machino, R. and Nagayasu, T. (2016) Management of Unexpected Intraoperative Bleeding during Thoracoscopic Pulmonary Resection: A Single Institutional Experience. Surgery Today, 46, 901-907. https://doi.org/10.1007/s00595-015-1253-9

[24] The Project to Collect Medical Near-Miss/Adverse Event Information of the Japan Council of Quality Health Care. http://www.med-safe.jp/contents/english/index.html

[25] McKenna Jr., R.J., Houck, W. and Fuller, C.B. (2006) Video-Assisted Thoracic Surgery Lobectomy: Experience with 1,100 Cases. The Annals of Thoracic Surgery, 81, 421-425. https://doi.org/10.1016/j.athoracsur.2005.07.078 
[26] Villamizar, N.R., Darrabie, M., Hanna, J., Onaitis, M.W., Tong, B.C., D’Amico, T.A. and Berry, M.F. (2013) Impact of T Status and N Status on Perioperative Outcomes after Thoracoscopic Lobectomy for Lung Cancer. The Journal of Thoracic and Cardiovascular Surgery, 145, 514-520. https://doi.org/10.1016/j.jtcvs.2012.10.039

[27] Roviaro, G., Varoli, F., Vergani, C., Maciocco, M., Nucca, O. and Pagano, C. (2004) Video-Assisted Thoracoscopic Major Pulmonary Resections: Technical Aspects, Personal Series of 259 Patients, and Review of the Literature. Surgical Endoscopy, 18, 1551-1558. https://doi.org/10.1007/s00464-004-6006-6

[28] Puri, V., Patel, A., Majumder, K., Bell, J.M,, Crabtree, T.D., Krupnick, A.S., Kreisel, D., Broderick, S.R,, Patterson, G.A. and Meyers, B.F. (2015) Intraoperative Conversion from Video-Assisted Thoracoscopic Surgery Lobectomy to Open Thoracotomy: A Study of Causes and Implications. The Journal of Thoracic and Cardiovascular Surgery, 149, 55-61, 62.e1. https://doi.org/10.1016/j.jtcvs.2014.08.074

[29] Stephens, N., Rice, D., Correa, A., Hoffstetter, W., Mehran, R., Roth, J., Walsh, G., Vaporciyan, A. and Swisher, S. (2014) Thoracoscopic Lobectomy Is Associated with Improved Short-Term and Equivalent Oncological Outcomes Compared with Open Lobectomy for Clinical Stage I Non-Small-Cell Lung Cancer: A Propensity-Matched Analysis of 963 Cases. European Journal of Cardio-Thoracic Surgery, 46, 607-613. https://doi.org/10.1093/ejcts/ezu036

[30] Liang, C., Wen, H., Guo, Y., Shi, B., Tian, Y., Song, Z. and Liu, D. (2013) Severe Intraoperative Complications during VATS Lobectomy Compared with Thoracotomy Lobectomy for Early Stage Non-Small Cell Lung Cancer. Journal of Thoracic Disease, 5, 513-517.

[31] Samson, P., Guitron, J., Reed, M.F., Hanseman, D.J., Sandra, L. and Starnes, S.L. (2013) Predictors of Conversion to Thoracotomy for Video-Assisted Thoracoscopic Lobectomy: A Retrospective Analysis and the Influence of Computed Tomography-Based Calcification Assessment. The Journal of Thoracic and Cardiovascular Surgery, 145, 1512-1518. https://doi.org/10.1016/j.jtcvs.2012.05.028

[32] Nicastri, D.G., Wisnivesky, J.P., Litle, V.R., Yun, J., Chin, C., Dembitzer, F.R. and Swanson, S.J. (2008) Thoracoscopic Lobectomy: Report on Safety, Discharge Independence, Pain, and Chemotherapy Tolerance. The Journal of Thoracic and Cardiovascular Surgery, 135, 642-647. https://doi.org/10.1016/j.jtcvs.2007.09.014

[33] Demmy, T.L., James, T.A., Swanson, S.J., McKenna Jr., R.J. and D’Amico, T.A. (2005) Troubleshooting Video-Assisted Thoracic Surgery Lobectomy. The Annals of Thoracic Surgery, 79, 1744-1752.

https://doi.org/10.1016/j.athoracsur.2004.05.015

[34] Berry, F.B. (2015) Pulmonary Artery Bleeding During Vide-Assisted Thoracoscopic Surgery. Intraoperative Bleeding and Control. Thoracic Surgery Clinics, 25, 239-247. https://doi.org/10.1016/j.thorsurg.2015.04.007 